\title{
Interphase ribosomal RNA cistron silver staining in refractory anaemias with and without excess blasts
}

\author{
N N Mamaev, G N Salogub, I B Nefedova
}

\begin{abstract}
Aim-To evaluate the haemopoietic function of bone marrow blood forming cells in human myelodysplastic syndromes (MDS) by silver staining of nucleolar organiser regions (AgNORs).

Methods-Nucleoli were investigated in bone marrow blast cells and in erythroid, granulocytic, and megakaryocytic cells from 12 haematologically healthy subjects, and from 26 patients with MDS, including 14 with refractory anaemia (RA), nine with $R A$ with excess blasts (RAEB), and three with RAEB in transformation (RAEB-t). The investigation was performed before treatment using a one step silver staining method. In each case 50 to 100 blasts, promyelocytes, myelocytes, immature (pronormoblastic and basophilic normoblastic) and mature (polychromatic normoblastic) erythroid elements, and megakaryocytes were evaluated for the mean numbers of nucleoli and AgNORs per nucleus. Student's $t$ test was used to compare the patient and control groups. Other statistical analyses were carried out by the computer assisted "HEMA" system.
\end{abstract}

Results-Compared with controls, the number of AgNORs in blasts, promyelocytes, immature erythroid elements, and megakaryocytes was decreased, whereas in myelocytes and polychromatic normoblasts it was similar. There was also a difference in the AgNOR scores in blood forming cells from patients with RAEB/ RAEB-t $v$ RA.

Conclusions-The loss of AgNOR sites in cellular series in MDS may result from the decrease of their proliferative potential with disease progression, intrinsic defects in maturation, and extensive apoptosis. (F Clin Pathol: Mol Pathol 1997;50:92-95)

Keywords: myelodysplastic syndromes; secondary acute staining

Internal Medicine

Pavlov Medical

University of St

Petersburg, Leo Tolstoi

str., 6/8, St Petersburg, 197089, Russia

N N Mamaev

G N Salogub

I B Nefedova

Correspondence to: Dr Nikolai Mamaev. elodysplastic syndromes (MDS) are pathic haematological disorders characterised by refractory cytopenias of one or more bone marrow cell lineages. Refractory anaemia (RA) is the most common haematological finding in MDS therefore its pathogenesis has been studied more extensively than that of granulocytopoiesis, megakaryocytopoiesis, etc. The evaluation of erythropoiesis in MDS by myeloid leukaemia; nucleolar organiser regions; silver

ferrokinetic techniques showed reduction in total erythroblast numbers, erythrocyte production, and lifespan. ${ }^{12}$ Measurements of S- $\mathrm{G}_{2} / \mathrm{M}$-phase DNA content by flow cytometry demonstrated that in MDS the number of cells in $G_{0} / G_{1}$ was significantly lower than normal in five of 24 RA patients with a correspondingly higher number of cells in $\mathrm{G}_{2} / \mathrm{M}^{3}$ It is noteworthy that a tendency towards a decreased number of cells in $S-G_{2} / M$ was also found in RA patients with excess blasts (RAEB). ${ }^{45}$ Using a new immunocytochemical and flow cytometry technology Jensen et al have recently observed significant differences in the proliferative potential of erythroid progenitor fractions in RA patients compared with normal controls and its pronounced decrease with disease progression. ${ }^{6}$ Finally, an increased proliferative capacity of blasts, and granulocytic and erythroid series, together with extensive apoptosis was revealed recently using a $\mathrm{Ki}-67$ antibody labelling technique. ${ }^{7}$ The AgNOR method is a cheap and readily available applied alternative to the aforementioned techniques for assessing cell proliferation states. Our findings in patients with leukaemia have shown that the number of AgNORs in bone marrow haemapoietic progenitors closely reflects their proliferative potential, ${ }^{8-10}$ the level of differentiation and maturation, ${ }^{11}$ and the degree of nuclear ploidy. ${ }^{12}{ }^{13}$ The aim of this work was to investigate the mean numbers of nucleoli and AgNORs in bone marrow blasts, erythroid, granulocytic, and megakaryocytic elements from haematologically healthy controls and from 26 patients with different stages of MDS (RA $v$ RAEB/RAEB in transformation (RAEBt)).

\section{Patients and methods}

The investigation was performed on 26 untreated adult patients with MDS, including 14 with RA, and 12 with RAEB and RAFB-t, who were admitted to our institution. MDS cases were diagnosed from typical clinical and haematological signs, and from cytogenetic findings. Twelve haematologically healthy subjects acted as controls.

Bone marrow smears taken by sternum puncture were air dried, fixed in methanolglacial acid mixture (3:1), and rinsed thoroughly with distilled water. After repeated air drying the preparations were put into $2 \mathrm{~N}$ formic acid for 10 minutes, rinsed again and impregnated with a mixture of $50 \%$ aqueous solution of silver nitrate with gelatin at $68^{\circ} \mathrm{C}$ for 
Table 1 Clinical findings, laboratory tests, and nucleolar silver staining data from patients with different variants of myelodysplastic syndromes (MDS). Values are means (SEM)

\begin{tabular}{|c|c|c|c|c|c|c|c|c|c|c|c|c|c|}
\hline \multirow[b]{3}{*}{ MDS types } & \multirow{3}{*}{$\begin{array}{l}\text { Patients } \\
\text { (n) }\end{array}$} & \multirow{3}{*}{$\begin{array}{l}\text { Mean age } \\
\text { (years) }\end{array}$} & \multicolumn{5}{|c|}{ Laboratory tests } & \multicolumn{6}{|c|}{ Nucleolar silver staining data } \\
\hline & & & \multicolumn{5}{|l|}{ Blasts } & \multicolumn{6}{|c|}{ Number of nucleoli (above); Number of AgNORs (below) } \\
\hline & & & $H b$ & $L$ & Plt & $p b$ & $b m$ & $B l$ & $\operatorname{Pr}$ & $M c$ & $E r-I$ & $E r-I I$ & $M g$ \\
\hline RA & 14 & $62.5(4.6)$ & $76(5)$ & $2.8(0.3)$ & $103(28)$ & $0(0)$ & $2.1(0.9)$ & $\begin{array}{l}2.8(0.2) \\
11.9(1.9)\end{array}$ & $\begin{array}{l}3.6(1.1) \\
15.7(5.1)\end{array}$ & $\begin{array}{l}3.9(1.1) \\
9.3(2.4)\end{array}$ & $\begin{array}{l}2.9(0.1) \\
20.2(6.6)\end{array}$ & $\begin{array}{l}4.2(0.1) \\
10.6(2.2)\end{array}$ & $\begin{array}{l}14.5(3.6) \\
45.7(7.3)\end{array}$ \\
\hline $\begin{array}{l}\text { RAEB and } \\
\text { RAEB-t }\end{array}$ & $9+3$ & $57.8(3.2)$ & $73(3.6)$ & $4.6(0.8)$ & $80.4(21)$ & $3(2)$ & $8.3(2.1)$ & $\begin{array}{l}2.5(0.7) \\
11.2(2.6)\end{array}$ & $\begin{array}{l}3.2(0.8) \\
11.3(2.6)\end{array}$ & $\begin{array}{l}3.5(0.3) \\
8.2(0.6)\end{array}$ & $\begin{array}{l}3.2(0.6) \\
15.6(2.6)\end{array}$ & $\begin{array}{l}4.3(0.8) \\
10.2(1.6)\end{array}$ & $\begin{array}{l}13.9(1.8) \\
44.9(2.8)\end{array}$ \\
\hline
\end{tabular}

$\mathrm{Hb}=$ haemoglobin $; \mathrm{L}=$ leucocytes $; \mathrm{Plt}=$ platelets $\mathrm{pb}=$ peripheral blood $; \mathrm{bm}=$ bone marrow $\mathrm{Bl}=$ blasts; $\mathrm{Pr}=$ promyelocytes; $\mathrm{Mc}=$ myelocytes;

$\mathrm{Er}-\mathrm{I}=$ pronormoblasts and basophilic normoblasts; Er-II = polychromatic normoblasts; $\mathrm{Mg}=$ megakaryocytes; RA = refractory anaemia; RAEB = refractory anaemia with excess blasts; RAEB-t = refractory anaemia with excess blasts in transformation.

four minutes (after Howell and Black ${ }^{14}$ with slight modification ${ }^{7}$ ). The preparations were then counterstained with $2 \%$ Giemsa for 20 seconds.

In each case 50 to 100 blasts, promyelocytes, myelocytes, erythroid elements of the first (Er-I) and second (Er-II) classes (Er-I, pronormoblasts and basophilic normoblasts; Er-II, polychromatic normoblasts), and megakaryocytes were evaluated for the mean numbers of nucleoli and AgNORs. Student's $t$ test was used to compare the patient and control groups. Other statistical analyses, including correlation tests, were done using the computer assisted "HEMA" system. ${ }^{15}$

\section{Results}

Clinical findings and the results of nucleolus silver staining of bone marrow cells from controls and from MDS patients are presented in table 1 and figure 1 .

REFRACTORY ANAEMIA

In controls and patients with $R A$ the fewest numbers of nucleoli were found in blasts and immature erythroid elements. Numbers were intermediate in promyelocytes, myelocytes, and polychromatic normoblasts, and much greater in megakaryocytes. Compared with controls, the mean numbers of nucleoli in blasts and Er-II tended to increase (the difference between indices was insignificant). In Er-I and megakaryocytes the mean numbers of nucleoli in blasts were significantly decreased ( $p<0.005$ and $p<0.001$, respectively)

In controls and patients with $R A$ the maximum numbers of AgNORs per nucleus were found in megakaryocytes, followed by immature erythroid elements (Er-I). The counts were intermediate in blasts, promyelocytes, and Er-II elements, and lowest in myelocytes. Despite the high proliferative state of basic blood forming elements in patients with RA the expected elevation of ribosomal cistron activity was not detected. The numbers of nucleoli in blasts correlated with those of promyelocytes $(r=0.68, \mathrm{p}<0.002)$, immature erythroid elements $(r=0.6, \mathrm{p}<0.009)$ and megakaryocytes $(r=0.64, \mathrm{p}<0.02)$. The numbers of nucleoli in promyelocytes correlated with those of Er-I $(r=0.61, \mathrm{p}<0.008)$, in myelocytes the numbers of nucleoli correlated closely with that of $\operatorname{Er}-\mathrm{I} \quad(r=0.69$, $\mathrm{p}=0.001)$ and Er-II $(r=0.58, \mathrm{p}<0.015)$.
The AgNOR score of promyelocytes corre- $\$$ lated closely with that of blasts $(r=0.7, \vec{\circ}$ $\mathrm{p}<0.015)$, Er-I $(r=0.86, \mathrm{p}<0.0001)$, myelocytes $(r=0.71, \mathrm{p}<0.00001)$, and with the $\vec{\omega}$ content of bone marrow myelocytes $(r=0.5$, $\mathrm{p}<0.038)$ and platelets $(r=0.5, \mathrm{p}<0.035)$. In addition, the percentage of bone marrow promyelocytes showed significant correlation with the number of bone marrow myelocytes $N$

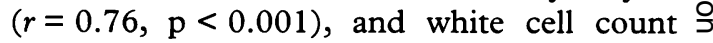
$(r=0.8, \mathrm{p}<0.0001)$. The numbers of AgNORs in erythroid elements correlated closely with the numbers of these cells in bone marrow $(r=0.61, \mathrm{p}<0.01)$. In megakaryocytes the numbers of nucleoli closely correlated with the level of haemoglobin $(r=0.72, \mathrm{p}<0.0003)$; the numbers of AgNORs depended on the indices of polychromatic normoblasts $(r=0.83, \mathrm{p}<0.00001)$ as well as on the peripheral blood content of plasma cells $(r=1.0, \quad \mathrm{p}<0.00001)$ and erythrocytes $(r=0.67, \mathrm{p}<0.002)$. No correlation between AgNORs in blasts and myelocytes was observed.

REFRACTORY ANAEMIAS WITH EXCESS BLASTS

Compared with controls, the patients with RAEB and RAEB-t had a decrease in numbers of nucleoli, not only in immature erythroid elements and megakaryocytes but also in promyelocytes and myelocytes. In addition, the mean numbers of nucleoli were similar in blasts, Er-I, and controls.

Compared with nucleoli counts, the changes of AgNORs in blood forming elements from patients with RAEB and RAEB-t were striking. The mean numbers of AgNORs were noticeably decreased in blasts ( $\mathrm{p}<0.001$ ), promyelocytes $(p<0.05)$, Er-I $(p<0.001)$, Er-II $(\mathrm{p}<0.002)$, and megakaryocytes $(\mathrm{p}<0.001)$. The difference between AgNOR counts in blasts, promyelocytes, myelocytes, and polychromatic normoblasts from patients with RAEB and RAEB-t, and those with RA was also significant ( $p<0.01$ to $p<0.0001)$. It is also noteworthy that some lower AgNOR counts in the group were detected in patients with RAEB-t whose percentages of blasts in bone marrow and peripheral blood were the highest but haemoglobin concentration and platelet counts were very low.

Additional analysis showed that the AgNOR counts in blasts from patients with RAEB was inversely proportional to those of polychromatic normoblasts $(r=-0.81, \mathrm{p}<0.0004)$ 

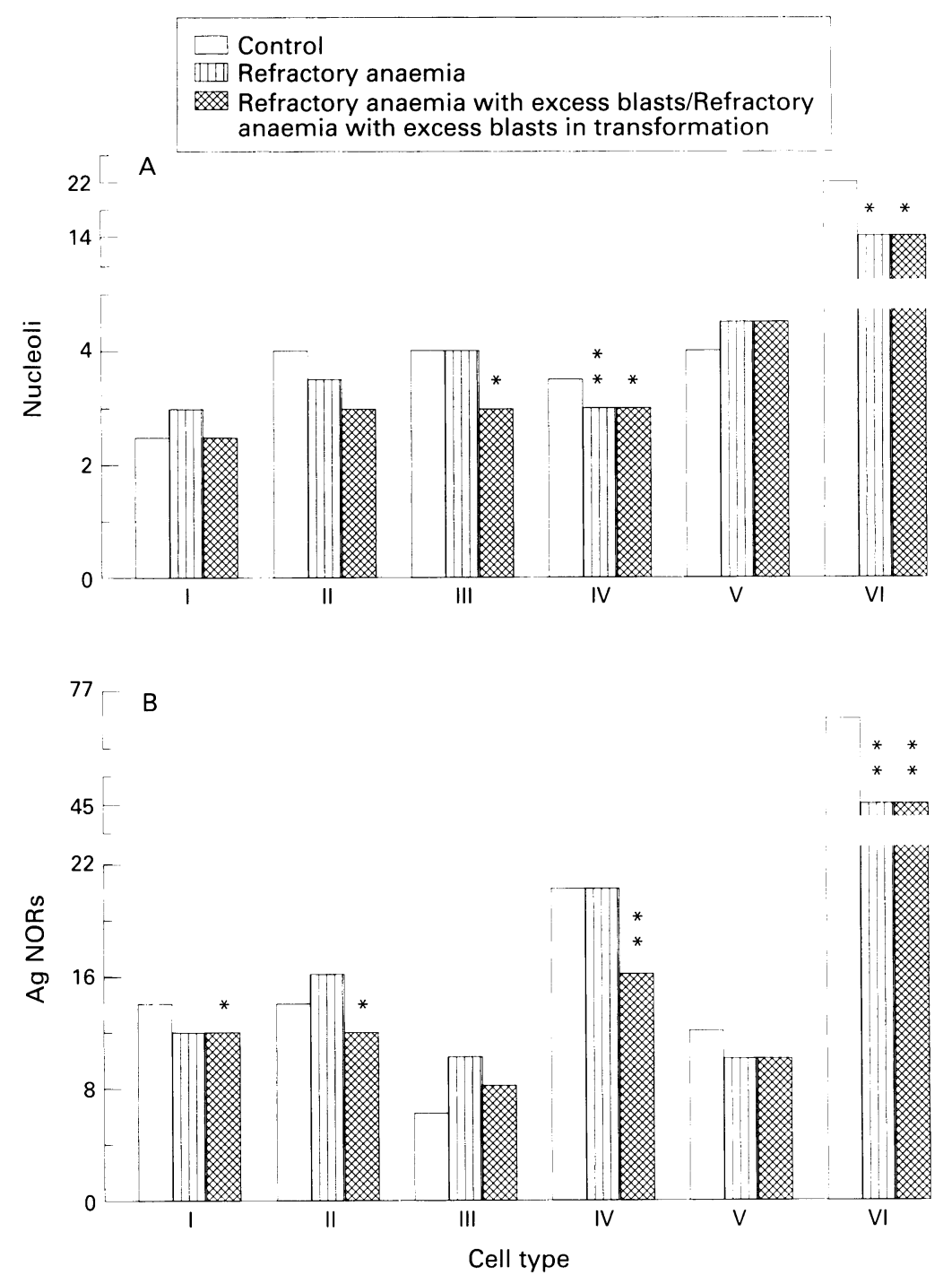

Figure 1 The mean number of nucleoli $(A)$ and the average number of AgNORs (silver stained nucleolar organiser regions) (B) per nucleus in bone marrow blasts (I), promyelocytes (II), myelocytes (III), pronormoblasts and basophilic normoblasts (IV), polychromatic normoblasts (V), and megakaryocytes (VI) from healthy controls and patients with myelodysplastic syndromes. ${ }^{\star} p<0.01,{ }^{\star \star} p<0.001, R A$ and $R A E B$ versus control.

and myelocytes $(r=-0.55, \mathrm{p}<0.05)$ which seemed to result from the direct inhibitory effect of blasts on RAEB haematopoiesis at the level of maturating erythroid and granulocyte elements. In contrast, the percentage of bone marrow blasts and the mean numbers of nucleoli in blasts were correlated closely with the content of immature erythroid elements in bone marrow $(r=0.82, \mathrm{p}<0.0002)$ and their AgNOR nucleoli counts $(r=0.78$, $\mathrm{p}<0.0006)$. Moreover, a highly significant correlation was also found between the numbers of erythrocytes and the numbers of nucleoli in maturating erythroid elements $(r=0.78, \mathrm{p}<0.0006)$.

\section{Discussion}

This study evaluated haematopoiesis in different stages of MDS by enumerating the interphase ribosomal RNA cistron silver staining. Compared with controls, patients with a stable clinical course (RA and RAS) had a tendency to lower AgNOR scores. In addition, a significant loss of AgNORs was found in erythroid elements, promyelocytes, megakaryocytes, and blasts of patients with RAEB and RAEB-t. Since the numbers of AgNORs in haemapoietic cells reflects their proliferative potential, the level of differentiation, and the degree of nuclear ploidy, the decrease of AgNORs in MDS patients might be attributed to some changes in these cellular parameters. Indeed, the degree of nuclear ploidy in MDS megakaryocytes is known to be much lower than that in controls. ${ }^{16}{ }^{17}$ Therefore, low AgNOR counts in RA and RAEB non-proliferating megakaryocytes may be explained by hypopolyploidy of their nuclei. Indeed, it was mentioned earlier that proliferative activity of erythroid elements from patients with MDS was higher than that of controls only in the stable stages of disease, essentially decreasing with progression of MDS from RA to RAEB-t. Thus, our AgNOR score in blood forming elements from RA and RAEB patients was in good accord with recently published findings in relation to the progression from RA to RAEB and RAEB-t. The absence of the expected increase of ribosomal cistron activity in haemapoietic progenitors at the RA stage might be explained by extensive apoptosis. ${ }^{7}$ 
Our findings showed that the AgNOR score in promyelocytes from patients with RA correlated closely with those of blasts $(r=0.7), \mathrm{Er}-\mathrm{I}$ $(r=0.86)$, myelocytes $(r=0.71)$, and with the content of bone marrow myelocytes $(r=0.5)$. In addition, the percentage of bone marrow promyelocytes showed a significant correlation with the numbers of bone marrow myelocytes $(r=0.76)$ and white cell count $(r=0.8)$. In general these findings indicate a key role of promyelocytes but not blasts (as shown previously in chronic myeloid leukaemia ${ }^{11}$ ) in RA haematopoiesis. In this context, it is noteworthy that the AgNOR score in promyelocytes was inversely associated with their content in bone marrow ( $r=-0.65, \mathrm{p}<0.003)$, suggesting a preservation of some feedback mechanisms at this stage of myelopoiesis. In contrast, the numbers of AgNORs in Er-I and Er-II were correlated closely with the numbers of these cells in bone marrow $(r=0.61, \mathrm{p}<0.01)$. Therefore, there may be a disturbance in a similar feedback regulation in RA erythropoiesis.

According to our findings, a possible inhibitory effect on MDS haemopoiesis was present at the level of polychromatic normoblasts and myelocytes from patients with RAEB. This conclusion was based on a strong negative correlation between the AgNOR counts in blasts and polychromatic normoblasts and myelocytes. Compared to blasts, AgNOR counts in RA and RAEB megakaryocytes correlated well with those in polychromatic normoblasts and with the numbers of erythrocytes. In our opinion, this observation suggests that megakaryocytic and erythroid lineages arise from a common precursor and have very similar mechanisms controlling gene expression.

In conclusion, the AgNOR data illustrate the usefulness of this method for detailed evaluation of aspects of haematopoiesis in physiological and pathological conditions. Moreover, there is some indirect evidence that megakaryocytes can participate in a microenvironment and/or stroma support and restoration, including haematopoiesis of patients with RA and RAEB.
1 Singh $\mathrm{AD}$, Shinton NK, Williams JDF. Ferrokinetic abnormalities and their significance in patients with sideroblastic anaemia. Br f Haematol 1970;18:67-77.

2 Koeffler HP, Cline MJ, Golde DW. Erythropoiesis in preleukemia. Blood 1978;51:1013-9.

3 Peters SW, Clark RE, Hoy TG, Jacobs A. DNA content and cell cycle analysis of bone marrow cells in myelodysplastic syndromes (MDS). Br f Haematol 1986;62:239-45.

4 Montecucco C, Ricardi A, Traversi E, Giordano P, Mazzuni 으 G, Ascari E. Proliferative activity of bone marrow cells in $T$ primary dysmyelopoietic (preleukemic) syndromes. Cancer 1983;52:1190-5.

5 Backx B, Broeders L, Hoefsloot LH, Wognum B, Lowenberg B. Erythropoiesis in myelodysplastic syndrome: expression of receptor for erythropoietin and kit ligand. Leukemia 1996;10:466-72.

6 Jensen IM, Hokland M, Hokland P. A quantitative evaluation of erythropoiesis in myelodysplastic syndromes using multi-parameter flow cytometry. Leuk Res 1993;17: 839-46.

7 Raza A, Mundles S, Iftikhar A, Gregory S, Marcus B, Khan $\mathrm{Z}$, et al. Simultaneous assessment of cell kinetics and programmed cell death in bone marrow biopsies of myelodysplastics reveals extensive apoptosis as the probable basis for in 995;48:14354

8 Mamaev NN, Martinez H, Morozova EO, Ivanova NA Characteristics of Ag-stained nucleoli in blasts of various diameters from patients with acute leukemias [Russian]. Tsitologiva 1988;30:1478-82.

9 Mamaev N, Mamaeva S. Nucleolar organizer region activity in human chromosomes and interphase nuclei of normal, N leukemic, and tumor cells as evaluated by silver staining. Int Rev Cytol 1990;121:233-66.

10 Mamaev NN, Mamaeva SE, Liburkina IL Kozlova TV, Medvedeva NV, Makarkina GN. The activity of nucleolar organizer regions (NOR's) of human bone marrow cells studied with silver staining. I. Chronic myelocytic leukemia. Cancer Genet Cytogenet 1985;16:31 1-20.

11 Mamaev NN, Salogub GN, Koloskov AV. Interphase ribosomal RNA cistron staining in chronic myeloid leukemia. $\mathcal{F}$ Clin Pathol: Mol Pathol 1995;48:M260-4.

12 Mamaev NN, Mamaeva SE. The structure and function of nucleolar organizer regions (NORs): Molecular, cytological, and clinical aspects [Russian]. Tsitologiya 1992;34(10): $3-25$.

13 Mamaev NN, Grichanova TI, Shandlorenko DS, Koloskov AV. Morphological and functional characteristics in normal and pathological megakaryocytes as evaluated by silver staining [Russian]. Gematol Transfuziol 1990;35(11):17-20.

14 Howell WM, Black DA. Controlled silver staining of nucleolus organizer regions with a protective colloidal developer: a one step method. Experientia 1980;36:1014-5.

15 Henkin A, Mamaev N. Information structures of bone marrow and blood detected with PC-based "HEMA" system (theoretical approaches and clinical practice) [abstract]. International Meeting ISH, Basel, Switzerland, August 31-September 6. Basel: Schwabe and Co, AG Verlag,
1991:134. 1991:134

16 Kobayashi Y, Kimura S, Tanaka K, Wada K, Ozawa M, Horiuchi $\mathrm{H}$, et al. Megakaryocyte ploidy in a MDS patient during a remission state. Int $\mathcal{F}$ Haematol 1991;54(Suppl 1): 113 .

17 Kobayashi Y, Ozawa M, Maruo N, Kondo M. Megakaryocytic ploidy in myelodysplastic syndromes. Leuk Lymphoma 1993;9:55-61. 